\title{
CEREBRAL NEAR-INFRARED SPECTROSCOPY IN TERM NEWBORNS: REFERENCE VALUES AND HYPOXIC-ISCHEMIC ENCEPHALOPATHY
}

\author{
Gumulak $R^{1}$, Nandraziova L ${ }^{1}$, Tulejova $L^{2}$, Pazicka $Z^{1}$ \\ ${ }^{1}$ Clinic of Neonatology, Jessenius Faculty of Medicine in Martin, Comenius University in Bratislava, \\ and Martin University Hospital, Martin, Slovakia. \\ ${ }^{2}$ Clinic of Anesthesiology and Intensive Medicine, Jessenius Faculty of Medicine in Martin, \\ Comenius University in Bratislava, and Martin University Hospital, Martin, Slovakia
}

\begin{abstract}
A b s tract
Non-invasive measurement of cerebral tissue oxygenation $\left(\mathrm{cStO}_{2}\right)$ using near-infrared spectroscopy (NIRS) is attracting an increasing attention not only in neonatology. The vast diversity of commercially available NIRS devices makes it difficult to compare in the published clinical studies. This review provides a view on the practical use of NIRS as a tool for $\mathrm{CStO}_{2}$ measurement, its limitations and pitfalls, with a focus on brain dysfunction caused by hypoxic-ischemic encephalopathy. This syndrome of disturbed neurologic function in the earliest days after the birth in the term infants is manifested by difficulty with initiating and maintaining respiration, depression of tone and reflexes, subnormal level of consciousness, and often seizures. This fascinating technology has already proven accurate and has been recommended to use during daily routine tool to evaluate the level of oxygen saturation in brain in intensive care units worldwide.
\end{abstract}

Key words: brain, hypoxic-ischemic encephalopathy, neonate, NIRS, oxygenation

\section{INTRODUCTION}

Non-invasive measurement of cerebral tissue oxygenation $\left(\mathrm{cStO}_{2}\right)$ using near-infrared spectroscopy (NIRS) is attracting an increasing attention in neonatology. This technology measures regional perfusion and oxygenation to provide a regional oxygen saturation level. As a bedside real-time technique it could help to identify under/over oxygenation levels in infants suffering from hypoxic-ischemic encephalopathy $(1,2)$. HIE is defined as a condition occurring in babies born over 35 weeks gestational age in which there is a disturbed neurological function (3). This syndrome of disturbed neurologic function in the earliest days after birth in the term infants is manifested by difficulty with initiating and maintaining respiration, depression of tone and reflexes, subnormal level of consciousness, and often seizures $(4,5)$. The overall incidence of HIE is about one to two babies per thousand term livebirths $(6,7)$.

\section{NEAR-INFRARED SPECTROSCOPY}

NIRS has been introduced in clinical practice as a tool to measure regional perfusion and oxygenation to provide real-time tissue oxygenation. All NIRS devices emit light at wavelengths within $700-1,000 \mathrm{~nm}$ and analyse photons returning to the transducer $(1,8)$. However, the difference between the light emitted and the light measured is not only caused by absorption but also by scattering. If scattering is assumed to be equal for the different detectors, absolute values can be measured and oxyHb (oxyhemoglobin) and $\mathrm{dHb}$ (deoxyhemoglobin) can be calculated into ratio-based percentage oxygen saturation (oxyHb/ (oxyHb+dHb); range 0 to 100\%) using different algorithms and methods (Table 1) (9-12). Recent NIRS based devices obtain estimates of total cerebral oxygenation: TOI (Tissue

Corresponding author: Lenka Tulejova, MD; e-mail: tulejova3@uniba.sk

(c) 2019 Gumulak R et al.

This work is licensed under the Creative Commons Attribution-NonCommercial-NoDerivs 4.0 License (https://creativecommons.org/licenses/by-nc-nd/4.0/) 
Oxygenation Index) or $\mathrm{StO}_{2}$ (regional oxygen saturation). This indifferent nomenclature is rather confusing: both indexes are used to calculate the fractional tissue oxygen extraction (FTOE), which represents the balance between oxygen supply and oxygen consumption. Modern devices incorporate the same technology but they differ in the number and absolute value of wavelengths, as well as in mathematic algorithms to translate the measured changes in light to absolute values $(11,12)$.

Table 1 Most used NIRS based devices for tissue oxygenation measurements $(1-3,11-13)$

\begin{tabular}{|c|c|c|c|}
\hline Type & Number of sensors & Manufacturer & Info \\
\hline FORE-SIGHT $^{\circledR}$ & 2 & Casmed, USA & www.casmed.com \\
\hline FORE-SIGHT Elite $^{\circledR}$ & 4 & Casmed, USA & www.casmed.com \\
\hline INVOS $^{\text {TM }} 5100 \mathrm{C}$ & $2-4$ & Comanetics, USA & www.somanetics.com \\
\hline NIMO $^{\text {TM }}$ & 4 & NIROX, Italy & www.nirox.it \\
\hline NIRO-200NX $^{\text {TM }}$ & 2 & Hamamatsu, Japan & www.hamamatsu.com \\
\hline O2C $^{\text {TM }}$ & 2 & LEA, Germany & www.lea.de \\
\hline OxiplexTS $^{\text {TM }}$ & 2 & ISS, USA & www.iss.com \\
\hline TRS $^{\text {TM }}$ & 2 & Hamamatsu, Japan & www.hamamatsu.com \\
\hline EQUANOX 760 $^{\text {TM }}$ & 2 & Nonin, USA & www.nonin.com \\
\hline ROOT $^{\circledR}$ & 2 & Masimo, USA & www.masimo.com \\
\hline T.oX $^{\text {TM }}$ & & ViOptix, USA & www.vioptix.com \\
\hline
\end{tabular}

A comparison of absolute values (cerebral, splanchnic, renal area) measured by different devices can be difficult (12). Name of the oxygenation saturation index may also vary: TOI $\left(\mathrm{NIRO}^{\circledR}\right.$, Hamamatsu Photonics, Japan), StO (INVOS $^{\mathrm{TM}} 5100$ Somanetics/Covidien, Mansfield, USA or FORE-SIGHT ${ }^{\circledR}$, Casmed USA) $(1,9)$.

\section{HYPOXIC-ISCHEMIC ENCEPHALOPATHY}

HIE is a disorder in which clinical manifestation indicates a brain dysfunction. Most underlying pathologic events of HIE are complex, including impaired cerebral blood flow, oxygen delivery, and they evolve over time $(13,14)$. However, the pathophysiologic effects of the hypoxic-ischemic insult are complex and evolve over time. The unfolding of signs and symptoms makes it difficult for health care providers to determine timely appropriate treatment options. The pathologic events of HIE occur in two phases: primary energy failure and secondary energy failure $(13,14)$. The extent of primary energy failure contributes to further injury in the secondary energy failure phase. The exact mechanisms of secondary energy failure remain unclear but appear to be related to oxidative stress overproduction of free radicals, which cause damage to neuronal cell membranes and lead to necrosis or apoptosis, excitotoxicity, and inflammation $(13,14)$. The latent period (after primary energy failure phase but before secondary) is considered the optimal timing for therapeutic interventions (14). The current successful treatment for infants with HIE is therapeutic hypothermia. It has been documented that this method is effective because it reduces free radicals and glutamate levels, decreases oxygen demand, and decreases apoptosis $(3,4,7)$. 


\section{REFERENCE VALUES FOR CEREBRAL OXYGENATION}

A large amount of studies based on NIRS monitoring of neonatal brain has been published, during neonatal transition or later life period during this unique period of human life. The published values were influenced by the gestational age, mode of the delivery, and the type of NIRS device used (15). Urlesberger et al. demonstrated that mean $\mathrm{cStO}_{2}$ during transition increased rapidly from $44 \%$ ( $3^{\text {rd }}$ minutes) to $76 \%$ ( $7^{\text {th }}$ minutes); thereafter no significant change occurred. They included 61 infants who were delivered via elective caesarean section. An INVOS 5100 ${ }^{\mathrm{TM}}$ (Somanetics, Troy, Michigan) device and left frontoparietal area were used. Cerebral fractional tissue oxygen extraction (cFTOE) decreased during the first minutes of life, by which values of the brain did not change significantly after 5 minutes (16). Recently demonstrated reference ranges and percentile charts for $\mathrm{cStO}_{2}$, $\mathrm{cFTOE}$ using INVOS $5100^{\mathrm{TM}}$ (Somanetics, Troy, Michigan) in the large cohort of term/preterm neonates found no significant differences comparing term and preterm neonates (17). Average $\mathrm{cStO}_{2}$ increased from 41.1 at $2^{\text {nd }}$ minute to 79.4 at $10^{\text {th }}$ minute and later slightly dropped to 77.5 in $15^{\text {th }}$ minute (17). Although, $\mathrm{CStO}_{2}$ of vaginally delivered neonates shows a decrease of up to $10 \%$ in value accompanied by the increase of FTOE after $8^{\text {th }}$ minute of age (18-20). Both the immediate postnatal adaptation and the following phase were assessed with mean $\mathrm{cStO}_{2}$ remaining between $70 \%$ and $80 \%$ during first 9 hours of life (NONIN EQUANOX ${ }^{\mathrm{TM}} 7600$ Regional Oximetry System, USA) (21). Taken together, most of the published studies expect mean reference values of $\mathrm{cStO}_{2}$ between $55 \%-85 \%$ (in \% values).

\section{HIE AND CEREBRAL OXYGEN SATURATION VALUES}

Therapeutic hypothermia soon after birth in the latent phase before the onset of secondary deterioration has been considered a feasible treatment in order to reduce the disabling neurodevelopmental sequelae of $\operatorname{HIE}(3,6,22)$. The study reported data from simultaneous aEEG (amplitude-integrated electroencephalography) and NIRS monitoring in newborns undergoing cooling following neonatal asphyxia suggested that TOI (NIRO ${ }^{\circledR}$, Hamamatsu Photonics, Japan) can be used as an early and reliable prognostic indicator of neurological outcome $(6,23)$. A higher TOI in infants with adverse outcome than with those with normal outcome has been documented $\left(80.0 \pm 10.5 \%\right.$ vs $66.9 \pm 7 \%, p=0.057$ at $6^{\text {th }}$ hour of life, $79.7 \pm 9.4 \%$ vs $67.1 \pm 7.9 \%, p=0.034$ in $12^{\text {th }}$ hour of life). The authors concluded that the aEEG background pattern at $24 \mathrm{~h}$ of life loses its positive predictive value after therapeutic hypothermia initialization (6). Other study published by Peng et al. observed a significant changes in $\mathrm{cStO}_{2}$ during the 72-hour duration of the hypothermia treatment, which led to important variations of oxygen demant/utilization. $\mathrm{cStO}_{2}$ was higher in the asphyxiated newborns who developed later brain injury. Sensitivity within the first 10 hours of hypothermia treatment for the adverse outcome was 100\% (95\% CI, 70 - 100\%) with a specificity of $83 \%$ (95\% CI, 36 - 99\%) (FORE-SIGHT ${ }^{\circledR}$, Casmed, USA). In all enrolled infants the authors noticed a decrease of $\mathrm{cStO}_{2}$ from $1^{\text {st }}$ hour to $4^{\text {th }}$ hour of the hypothermia treatment. This time range seems to be the only time when temperature has a significant impact on $\mathrm{CStO}_{2}$ and, thus, on the cFTOE (24). cFTOE remained stable in infants with normal outcome but decreased after 24 hours in infants with adverse outcome in different study (3, 25). Only a small number of studies showed combined use of aEEG and NIRS. Goeral et al. demonstrated this combination for outcome prediction in neonates cooled for HIE. For moderate HIE this double monitoring technique has proven as important predictors of shortterm outcome. The highest predictive ability was documented between 18 hours and 60 hours of therapeutic hypothermia (the addition of NIRS to aEEG led to an increase in specificity (from $52.4-59.1 \%$ to $72.7-90.5 \%)(15,26)$. The published data also showed a reduced predictive value of the evaluated scores after 60 hours and, therefore, their results might have been due to that unfavorable time point (26). However, in different study NIRS variables (INVOS $5100^{\mathrm{TM}}$, Somanetics, Troy, Michigan) did not differentiate between those with favorable $(n=13)$ versus adverse (death or moderate-severe disability; $n=5$ ) 18 -month out- 
comes. Systemic $\mathrm{cStO}_{2}$ variability was higher during hours 48 - 72 of cooling among those with favorable outcomes: mean aEEG amplitude during hours 24 to 48 of cooling was higher among those with good outcomes (27).

\section{CONCLUSION}

This review summarizes an overview of current state of NIRS technology in the field of neonatology as a tool for non-invasive feasible method. The results of recently published studies have shown that monitoring of cerebral oxygenation can have an important role to play in the setting of treatment management of HIE. However, the differences between NIRS based devices (different wavelengths, different computing algorithm translating measured changes into the total value) complicates the comparison between them. It has been documented that values can also depend on the type of probe used (28). Since they should be single-used, routine NIRS monitoring can be costly. Some authors pointed out that reapplication of sensors on the same region can result in degree of inaccuracy of up to 6\% (15, 29). More normative population-based data are needed in order to establish physiological values for different NIRS devices. Many different clinical conditions may complicate the NIRS values evaluation (hemoglobin concentration, blood pressure, persistent Ductus arteriosus Botalli, respiratory status, hyper/hypocapnia, and others) $(1,6,11,30)$. This should be mentioned and double checked, if possible, in every single study design. This field of neonatology has been extremely fascinating and evolving in recent years. As for screening tool for neurological outcome NIRS has already proven its simplicity and popularity as a power tool to be one step ahead in the treatment of our smallest and most vulnerable patients.

\section{REFERENCES}

1. Gumulak R, Lucanova LC, Zibolen M. Use of near-infrared spectroscopy (NIRS) in cerebral tissue oxygenation monitoring in neonates. Biomed Pap Med Fac Univ Palacky Olomouc Czech Republic 2017; 161(2): 128-33.

2. Chock VY, Davis AS. Bedside cerebral monitoring to predict neurodevelopmental outcomes. NeoReviews 2009; 10(3): 121-9.

3. Martinello K, Hart AR, Yap S, Mitra S, Robertson NJ. Management and investigation of neonatal encephalopathy: 2017 update. Archives of Disease in Childhood-Fetal and Neonatal Edition. 2017; 102(4): F346-58.

4. de Vries LS, Cowan FM. Evolving Understanding of Hypoxic-Ischemic Encephalopathy in the term infant. Seminars in Pediatric Neurology 2009; 16(4): 216-25.

5. Sarnat HB, Sarnat MS. Neonatal encephalopathy following fetal distress. A clinical and electroencephalographic study. Archives of Neurology 1976; 33: 696-705.

6. Ancora G, Maranella E, Grandi S, Sbravati F, Coccolini E, Savini S, Faldella G. Early predictors of short-term neurodevelopmental outcome in asphyxiated cooled infants. A combined brain amplitude integrated electroencephalography and near infrared spectroscopy study. Brain and Development. 2013; 1;35(1): 26-31.

7. Gunn AJ. Cerebral hypothermia for prevention of brain injury following perinatal asphyxia. Current Opinion Pediatrics 2000; 12: 111-5.

8. Owen-Reece H, Smith M, Elwell CE, Goldstone JC. Near infrared spectroscopy. British Journal of Anaesthesia 1999; 82(3): 418-26.

9. da Costa CS, Greisen G, Austin T. Is near-infrared spectroscopy clinically useful in the preterm infant? Archives of Disease in Childhood-Fetal and Neonatal Edition 2015; 100: 558-61.

10. Liem KD, Greisen G. Monitoring of cerebral haemodynamics in newborn infants. Early Human Development 2010; 86: 155-8. 
11. Korček P, Straňák Z, Širc J, Naulaers G. The role of near-infrared spectroscopy monitoring in preterm infants. Journal of Perinatology 2017; 37(10): 1070-7.

12. Sood BG, McLaughlin K, Cortez J. Near-infrared spectroscopy: applications in neonates. In Seminars in Fetal and Neonatal Medicine 2015; 20(3): 164-72.

13. Allen KA, Brandon DH. Hypoxic ischemic encephalopathy: pathophysiology and experimental treatments. Newborn and Infant Nursing Reviews 2011; 11(3): 125-33.

14. Cotten CM, Shankaran S. Hypothermia for hypoxicischemic encephalopathy. Expert Rev Obstet Gynecology 2010; 5: 227-39.

15. Garvey AA, Dempsey EM. Applications of near infrared spectroscopy in the neonate. Current opinion in pediatrics. 2018; 30(2): 209-15.

16. Urlesberger B, Grossauer K, Pocivalnik M, Avian A, Müller W, Pichler G. Regional oxygen saturation of the brain and peripheral tissue during birth transition of term infants. The Journal of pediatrics. 2010; 157(5): 740-4.

17. Pichler G, Binder C, Avian A, Beckenbach E, Schmölzer GM, Urlesberger B. Reference ranges for regional cerebral tissue oxygen saturation and fractional oxygen extraction in neonates during immediate transition after birth. The Journal of pediatrics. 2013; 163(6): 1558-63.

18. Pichler G, Cheung PY, Aziz K, Urlesberger B, Schmölzer GM. How to Monitor the Brain during Immediate Neonatal Transition and Resuscitation: A Systematic Qualitative Review of the Literature. Neonatology 2014;105(3): 205-10.

19. Kratky E, Pichler G, Rehak T, Avian A, Pocivalnik M, Müller W, Urlesberger B. Regional cerebral oxygen saturation in newborn infants in the first 15 min of life after vaginal delivery. Physiological measurement. 2011; 33(1): 95-102.

20. Isobe K, Kusaka T, Fujikawa Y, Okubo K, Nagano K, Yasuda S, Kondo M, Itoh S, Hirao K, Onishi S. Measurement of cerebral oxygenation in neonates after vaginal delivery and cesarean section using full-spectrum near infrared spectroscopy. Comparative Biochemistry and Physiology Part A: Molecular \& Integrative Physiology 2002; 132(1): 133-8.

21. Montaldo P, De Leonibus C, Giordano L, De Vivo M, Giliberti P. Cerebral, renal and mesenteric regional oxygen saturation of term infants during transition. Journal of pediatric surgery 2015; 50(8): 1273-7.

22. Battin MR, Dezoete JA, Gunn TR, Gluckman PD, Gunn AJ. Neurodevelopmental outcome of infants treated with head cooling and mild hypothermia after perinatal asphyxia. Pediatrics 2001; 107(3): 480-4.

23. Zimova Z, Matasova K, Zibolen M. Amplitude-Integrated Electroencephalography: Classification and Possibilities of Use in Practice. Acta Medica Martiniana. 2015; 15(1): 27-35.

24. Peng S, Boudes E, Tan X, Saint-Martin C, Shevell M, Wintermark P. Does near-infrared spectroscopy identify asphyxiated newborns at risk of developing brain injury during hypothermia treatment? American journal of perinatology 2015; 32(06): 555-64.

25. Awal MA, Lai MM, Azemi G, Boashash B, Colditz PB. EEG background features that predict outcome in term neonates with hypoxic ischaemic encephalopathy: A structured review. Clinical Neurophysiology 2016; 27(1): 285-96.

26. Goeral K, Urlesberger B, Giordano V, Kasprian G, Wagner M, Schmidt L, Berger A, KlebermassSchrehof K, Olischar M. Prediction of outcome in neonates with hypoxic-ischemic encephalopathy II: role of amplitude-integrated electroencephalography and cerebral oxygen saturation measured by near-infrared spectroscopy. Neonatology 2017; 112(3): 193-202.

27. Shellhaas RA, Kushwaha JS, Plegue MA, Selewski DT, Barks JD. An evaluation of cerebral and systemic predictors of 18-month outcomes for neonates with hypoxic ischemic encephalopathy. Journal of child neurology 2015; (11): 1526-31.

28. Alderliesten T, Dix L, Baerts W, Caicedo A, Van Huffel S, Naulaers G, Groenendaal F, van Bel F, Lemmers P. Reference values of regional cerebral oxygen saturation during the first 3 days of life in preterm neonates. Pediatric research 2016;79 (1-1):55-64.

29. Greisen G. Is near-infrared spectroscopy living up to its promises? Seminars in Fetal and Neonatal Medicine 2006; 11(6): 498-502. 
30. Pellicer, A., Greisen, G., Benders, M., Claris, O., Dempsey, E., Fumagally, M., Gluud, C., Hagmann, C., Hellström-Westas, L., Hyttel-Sorensen, S. and Lemmers, P. The SafeBoosC phase II randomised clinical trial: a treatment guideline for targeted near-infrared-derived cerebral tissue oxygenation versus standard treatment in extremely preterm infants. Neonatology 2013; 104(3): 171-8.

Received: April, 1, 2019

Accepted: May, 7, 2019 